\title{
NOTE TECHNIQUE : OBTENTION D'ANIMAUX TRIPLOIDES CHEZ LA TRUITE ARC-EN-CIEL
}

\author{
B. Chevassus *, E. QUILLET * * et D. CHOURROUT*
}

* Laboratoire de Physiologie des Poissons, I.N.R.A. - 78350 JOUY-en-JOSAS.

* Département de Biologie, Aquaculture et Pêche, C.N.E.X.O., B.P. 337 - 29273 BREST CEDEX.

\section{RÉSUMÉ}

Nous présentons dans cette note le protocole d'obtention d'animaux triploïdes par choc thermique chez la truite arc-en-ciel, ainsi que quelques indications sur l'intérêt et les caractéristiques zootechniques de ces animaux.

\section{SUMMARY}

A method to obtain triploid animals in rainbow trout by heat shock is described. Some indications on the practical interest and features of those triploids are given.

Chez les Salmonidés, l'obtention d'animaux ne présentant pas de maturation sexuelle apparaît intéressante dans plusieurs cas : en élevage intensif, elle permet d'envisager la production d'animaux de grande taille sans se heurter aux difficultés inhérentes à la maturation sexuelle (ralentissement de la croissance, mortalités plus élevées, diminution de la qualité de la chair) ; dans le cas de peuplements extensifs, elle autorise le déversement d'animaux dont on souhaite éviter la prolifération éventuelle ou le croisement avec les individus résidents.

Différentes méthodes ont été proposées pour aboutir à un tel résultat (CHEVASSUS et al., 1979 b; BILLARD, 1983). L'une d'entre-elles repose sur la création d'animaux triploïdes (possédant trois exemplaires de chaque chromosome au lieu de deux chez les individus normaux diploïdes) qui, selon plusieurs auteurs, montreraient un développement extrêmement réduit de la gonade, au moins chez les femelles (THORGAARD et GALL, 1979 ; LINCOLN et SCOTT, 1983). Au cours des trois dernières années, le laboratoire de Physiologie des Poissons de l'INRA a mis au point une méthode simple permettant l'obtention de tels animaux triploïdes chez la truite arc-en-ciel (CHOURROUT, 1980 ; CHOURROUT et QUILLET, 1982). Une telle méthode, combinée aux techniques de production de populations " monosexes femelles " (CHEVASSUS et al., 1979 a) pourrait donc fournir des populations contenant une très forte proportion d'animaux stériles. Elle est basée sur l'application d'un choc chaud peu après la fécondation qui, en inhibant la dernière étape de la méïose femelle, permet d'obtenir des individus présentant au niveau de leur noyau un stock génétique supplémentaire issu de leur mère, qui vient s'ajouter aux deux stocks génétiques d'origine maternelle et paternelle (apportés respectivement par l'ovule et le spermatozoïde) que possèdent les individus normaux diploïdes.

Nous présentons dans cette note technique :

- le protocole précis permettant l'obtention d'animaux triploïdes,

- quelques indications sur les caractéristiques zootechniques de ces animaux, basées sur nos observations des deux dernières années.

\section{PROTOCOLE}

La méthode consiste à tremper les œufs dans un bain-marie à $26^{\circ} \pm 0,5^{\circ} \mathrm{C}$ pendant $20 \mathrm{mn}$ peu après la fécondation. On procèdera de la manière suivante :

\section{1) Fécondation}

Nous distinguerons le cas où l'on utilise la méthode sèche traditionnelle et celui où l'on utilise le dilueur 532 pour l'insémination artificielle (BILLARD, 1977). Les quantités de sperme mentionnées sont celles utilisées traditionnellement en pisciculture. L'utilisation du dilueur permet de réduire éventuellement ces quantités (BILLARD, 1975). 
Compte tenu des caractéristiques du traitement (voir plus loin), il semble souhaitable de ne pas réaliser des mélanges de plus de 4 à 5 pontes (environ 20000 œufs).

Avec dilueur: les ovules sont égouttés, puis mélangés au sperme. On ajoute rapidement le dilueur dans les proportions : $20000 œ u f s+5$ à $10 \mathrm{cc}$ de sperme +500 à $700 \mathrm{cc}$ de dilueur (quantité suffisante pour recouvrir les œufs sous environ $1 \mathrm{~cm}$ de liquide).

Le mélange est laissé au repos $10 \mathrm{mn}$ puis mis dans l'eau dans les paniers d'incubation. On déclenche le minutage lors de cette mise dans l'eau. Dans le cas où les œufs sont rincés avant d'être mis en incubation, le minutage doit débuter au début du rinçage.

Sans dilueur : on ajoute l'eau au mélange ovules + sperme. C'est alors que l'on déclenche le minutage. 10 à $15 \mathrm{mn}$ après, les œufs sont lavés puis mis dans les paniers d'incubation.

\section{2) Première incubation}

Les œufs doivent rester $\mathbf{2 5}$ mn après le début du minutage dans une eau d'incubation à environ $10^{\circ} \mathrm{C} \pm 1^{\circ} \mathrm{C}$.

Pour s'assurer de la qualité des ovules et de la réussite du traitement, on constituera dans toute la mesure du possible deux petits lots témoins représentant un mélange des différentes séries de ponte et qui ne seront pas soumis au choc chaud

- un lot d'ovules qui sera mis dans un incubateur sans avoir été fécondé. Ce lot ne devra présenter le lendemain matin qu' un nombre d'œufs blancs extrêmement faible (moins de $5 \%$ ). Dans le cas contraire, la qualité des pontes est certainement médiocre.

- un lot d'ovules fécondés normalement. C'est par rapport à ce lot que le taux de réussite du traitement au stade œillé devra être jugé (voir II).

\section{3) Choc chaud}

On se procurera un bac de 50 à $100 \mathrm{I}$. pouvant recevoir directement les paniers d'incubation, afin d'éviter les transvasements au début et à la fin du choc chaud qui peuvent faire blanchir rapidement de nombreux œufs. Si la régulation thermique est assurée par une résistance, ne pas oublier qu'il faut environ 1 heure pour monter de $10^{\circ} \mathrm{C}$ à $26^{\circ} \mathrm{C}$ dans un bac de $50 \mathrm{l}$. avec une résistance de 1000 watts (et donc 2 heures pour 100 I.)

Il est donc préférable de mettre en route le bain-marie et de vérifier sa stabilité thermique avant le début des fécondations.

D'autre part, pour un bain-marie recevant une nouvelle série de 20000 œufs toutes les 10 minutes, une résistance d'au moins 1000 watts est nécessaire pour assurer la régulation thermique dans un local non chauffé.

$25 \mathrm{mn}$ après le début du minutage, les paniers sont posés doucement dans le bain-marie et agités pour équilibrer la température. II semble préférable de ne pas dépasser 20000 œufs par panier pour obtenir une équilibration rapide.

$2 \mathrm{mn}$ après le début du choc chaud, on vérifie avec un thermomètre plongé au milieu des cufs, que la température a dépassé $25^{\circ} \mathrm{C}$. Sinon, on continue à agiter lentement le panier.

Après $20 \mathrm{mn}$ dans le bain-marie, les paniers sont doucement remis dans les auges d'incubation et agités lentement quelques instants pour rééquilibrer la température.

\section{4) Durcissement}

A la sortie du choc chaud, les œufs ne sont pas encore durcis. Il faut donc attendre encore au moins $30 \mathrm{mn}$ pour pouvoir les manipuler pour transvasement, traitement au Romeiod ou nettoyages... 


\section{RENDEMENT DE LA METHODE}

Si des mortalités apparaissent dès le lendemain (œufs blancs), elles sont dues soit à des manipulations trop brutales des œufs, soit à une mauvaise qualité des ovules.

Dans ce cas, la comparaison au lot témoin " non fécondé " fournira une indication précieuse. En pratique normale et avec des ovules de bonne qualité, aucune augmentation décelable du taux d'ceufs blancs ne doit apparaître à 24 h.

Par contre, lors du tri au stade œillé, il faut compter une élimination d'environ 10 à $20 \%$ de plus d'œufs morts ou anormaux (petits yeux, taches hémorragiques). Cette proportion sera beaucoup plus forte en cas d'erreur dans le minutage (choc chaud trop précoce, ou trop tardif, trop long ou trop court) ou dans la température du bain-marie (trop chaud)

Sur la base de nos observations, nous donnons ci-dessous les bornes permettant d'obtenir des résultats encore acceptables

\begin{tabular}{|l|c|c|r|}
\hline \multicolumn{1}{|c|}{ Paramètre } & Optimum & Minimum & Molérance \\
\hline Durée de préincubation & $25 \mathrm{mn}$ & $15 \mathrm{mn}$ & $35 \mathrm{mn}$ \\
\hline Durée du choc chaud & $20 \mathrm{mn}$ & $15 \mathrm{mn}$ & $25 \mathrm{mn}$ \\
\hline $\begin{array}{l}\text { Température de choc } \\
\text { chaud }\end{array}$ & $26,5^{\circ} \mathrm{C}$ & $25,5^{\circ} \mathrm{C}$ & $27^{\circ} \mathrm{C}$ \\
\hline
\end{tabular}

Par contre, nous n'avons pas d'informations précises sur les tolérances concernant la température de préincubation. On essaiera donc de se rapprocher au maximum de la température de référence de $10^{\circ} \mathrm{C}$.

Pendant l'éclosion et au cours de la résorption, une nouvelle perte d'environ $10 \%$ est à prévoir (mortalités et animaux malformés) par rapport au témoin.

\section{CARACTÉRISTIQUES DES ANIMAUX TRIPLOIDES}

Nous ne donnerons ici que quelques indications sommaires, les études étant encore en cours.

\section{1) Survie et croissance en cours d'élevage}

Nos données actuelles portent sur la croissance et la survie au cours des deux premières années d'élevage dans des conditions de survie bonne mais de croissance assez lente. Nous observons

- une survie correcte des triploides, l'écart entre diploïdes et triploïdes étant généralement inférieur à $5 \%$ sur la période de 3 mois à 1 an

- une croissance plus lente des triploïdes, l'écart pouvant atteindre 20 à $25 \%$ en fin de première année. L'écart semble se restreindre au cours de la deuxième année, mais reste en faveur des diploïdes au début de la période de maturation sexuelle (septembre).

\section{2) Reproduction}

D'après nos premières observations, il apparaît que, comparativement à un témoin diploïde dont presque tous les animaux, mâles et femelles, sont matures à 2 ans, les triploides présentent au même âge

- des mâles dont le testicule est développé, conduisant à des rapports gonadosomatiques (gonade/carcasse) du même ordre que les diploïdes (6a $7 \%$ ). Ces testicules ne semblent cependant pas évoluer jusqu'à la spermiation.

- des femelles dont l'ovaire est généralement extrêmement réduit (moins de 1 gramme pour des animaux d'environ $800 \mathrm{~g}$ ) et ne semble pas susceptible d'évoluer ultérieurement. 
De ce fait, l'indice de carcasse (poids de carcasse rapporté au poids total du corps en \%) des femelles triploïdes est voisin de celui des témoins immatures (88 à $90 \%$ ) et nettement supérieur à celui des animaux matures (généralement inférieur à $85 \%$ ).

Des études plus précises de la composition corporelle, notamment au niveau des réserves lipidiques, sont cependant nécessaires pour préciser l'intérêt de ces animaux stériles.

\section{BIBLIOGRAPHIE}

* BILlARD R., 1975. L'insémination artificielle de la truite Salmo gairdneri Richardson $V$. Effet de la dilution et définition du rapport optimum gamètes/dilueur. $B u l l$. Francais Pisc., 257, 121-135.

* BILLARD R., 1977. Utilisation d'un système tris. glycocolle pour tamponner le dilueur d'insémination pour truite. Bull. Français Pisc., 264, 102-112.

* BILLARD R., 1983. Sur quelques possibilités de maîtriser la reproduction chez les poissons téléostéens. La Pisciculture Française, 67, 15-34.

* CHEVASSUS B., CHOURROUT D., JALABERT B., 1979 a. Le contrôle de la reproduction chez les poissons. I. Les populations" monosexes ". Bull. Français Pisc., 274. 32-46.

* CHEVASSUS B., BLANC J.M., CHOURROUT D., 1979 b. Le contrôle de la reproduction chez les poissons. II. Reproduction différée et stérilité. Bull. Français Pisc., 274, 18.31.

* CHOURROUT D., 1980. Thermal induction of diploid gynogenesis and triploidy in the eggs of the rainbow trout (Salmo gairdneri, Richardson). Reprod. Nutr. Develop., 20, 727-733.

* CHOURROUT D., QUILLET E., 1982. Induced gynogenesis in the rainbow trout : sex and survival of progenies. Production of All. triploid populations. Theor. Appl. Genet., 63, 201-205.

LINCOLN R.F. et SCOTT A.P., 1983. Production of all. female triplold rainbow trout. Aquaculture, 30, 373-380.

THORGAARD G.H. et GALL G.A.E., 1979. Adult triploïs in a rainbow trout family. Genetics, 93, $961-973$.

* Les articles peuvent être demandés au Laboratoire de Physiologie des Poissons I.N.R.A - 78350 JOUY-en-JOSAS. 